ON THE VALUE OF OPTIONS IN CERTAIN CONTRACTS.

\title{
To the Editor.
}

SIR,- - Mr. Stephenson's problem on "Options" continuing to excite a good deal of interest, I shall be obliged if you will allow me space for a somewhat full discussion of it.

As stated by Mr. Stephenson the problem is:-To find the single premium for an annuity [of $£ 1$ ] during the remainder of a life $(x)$ after $n$ years, with the condition that the premium is " returnable," without interest, on death or at the option of the purchaser, at any time prior to the commencement of the annuity.

To put this into shape for solution, Mr. S. directs us to consider the single premium, $P$, as a capital producing in interest $P r$ per annum; and that this interest, treated as a preminm payable at the end of the year, will purchase a certain amount of annnity, to be entered npon in $n$ years. Also, that the capital $P$ being then invested in the purchase of a further amount of annuity, since the whole of the annuity purchased is to be $E 1$, we shall have an equation that will enable us to determine $P$.

I remark in passing, that the portion of the benefit during the $n$ years here contemplated is slightly different from that in the problem. According to the latter the return is to be $P$, at the instant of death or withdrawal, the amount of which at the end of the year will be $\mathrm{P}(1+r)^{\frac{1}{2}}$. By the other arrangement the amonnt in the hands of $(x)$ or his representatives, at the same period, wonld be $\mathbf{P}(1+r)$, since, no preminm being payable during the year of death or withdrawal, the parties entitled will be in possession of both $\mathrm{P}$ and the interest on it for that year. This is a small matter, however.

Mr. Stephenson's solntion of the problem, as here modified, is equivalent to the following:-

The present value of the premium $\mathrm{Pr}$, payable at the end of each year for $n$ years, is

$$
\frac{\operatorname{Pr}\left(\mathrm{N}_{x}-\mathrm{N}_{x+n}\right)}{\mathrm{D}_{x}}
$$

and if $a$ be the annuity that this will parchase, we shall have

$$
\operatorname{Pr}\left(\mathrm{N}_{x}-\mathrm{N}_{x+n}\right)=a \mathrm{~N}_{x+n} ; \therefore a=\frac{\operatorname{Pr}\left(\mathrm{N}_{x}-\mathrm{N}_{x+n}\right)}{\mathrm{N}_{x+n}} \text {. }
$$

Also, if $a^{\prime}$ be the annuity that $\mathrm{P}$ will parchase at age $x+n$,

Hence, by condition,

$$
\mathrm{P}=\frac{a^{3} \mathrm{~N}_{x+n}}{\mathrm{D}_{x+n}} ; \quad \therefore a^{\prime}=\frac{\mathrm{PD}_{x+n}}{\mathrm{~N}_{x+n}} \text {. }
$$

which gives

$$
\frac{\mathrm{PD}_{x+n}+\operatorname{Pr}\left(\mathrm{N}_{x}-\mathrm{N}_{x+n}\right)}{\mathrm{N}_{x+n}}=a^{\prime}+a=1
$$

$$
\mathbf{P}=\frac{\mathrm{N}_{x+n}}{\mathrm{D}_{x+n}+r\left(\mathrm{~N}_{x}-\mathrm{N}_{x+n}\right)} \ldots . . .
$$

Now there is a gross paralogism in this process : the very first step is vicious. $\operatorname{Pr}\left(\mathrm{N}_{x}-\mathrm{N}_{x+n}\right) \div \mathrm{D}_{x}$ is the value of the premium $\mathrm{Pr}$ when it is determinable (during the first $n$ years) by the death of $(x)$ only; but it is 
not the value of the same premium when it is determinable also at the pleasure or the caprice of $(x)$ by the withdrawal of $P . *$ It is as representing this last-named valne that it is employed in the foregoing process, which is therefore vitiated thronghout. And the value of $P$ here found is that corresponding to the legitimate signification of the expression referred to; and consequently no provision is made in it for the option of withdrawal.

I shall show this otherwise. Mr. Stephenson's benefit, divested of the option clause, and supposing, as above, that the amount of the return at the end of the year of death is $P(1+r)$, consists of, first, an annuity of $\mathfrak{f} 1$, deferred $n$ years, whose present valne is $\frac{\mathrm{N}_{x+n}}{\mathrm{D}_{x}}$; and secondly, a temporary assurance for $n$ years of $P(1+r)$, whose present value is $\frac{\mathrm{P}(1+r)\left(\mathrm{M}_{x}-\mathrm{M}_{x+*}\right)}{\mathrm{D}_{x}}$. Hence

$$
\mathrm{PD}_{x}=\mathrm{N}_{x+n}+\mathrm{P}(1+r)\left(\mathrm{M}_{x}-\mathrm{M}_{x+n}\right)
$$

solution of which gives

$$
\mathrm{P}=\frac{\mathrm{N}_{x+n}}{\mathrm{D}_{x}-(1+r)\left(\mathrm{M}_{x}-\mathrm{M}_{x+n}\right)} \cdot \cdot \cdot \cdot .
$$

Now (1) and (2), are identical in value: each of them gives, for $x=50$ and $n=10$ (Carlisle, 4 per cent.), $\mathrm{P}=6 \cdot 30295$. And they will become identical in symbols also if in (2) we substitute for $M_{x}$ and $M_{x+n}$ their valnes as given by the relation $\mathrm{M}_{x}=\mathrm{D}_{x}-(1-v) \mathrm{N}_{x-1}=\mathrm{D}_{x}-(1-v)\left(\mathrm{D}_{x}+\mathrm{N}_{x}\right)$. It is thus abundantly shown (although it looks like trifling to offer formal demonstration of so plain a matter) that a method which ignores the probability of withdrawal does not, and cannot, assign the true value of a benefit which depends partly on that probability.

If the valne of $\mathrm{P}$ when returnable at the moment of death is required (and still, of course, withont the option of withdrawal), we have merely to write $(1+r)^{2}$ for $1+r$ in (2), which thas becomes

$$
\mathrm{P}=\frac{\mathrm{N}_{x+n}}{\mathrm{D}_{x}-(1+r)^{\frac{1}{(}\left(\mathrm{M}_{x}-\mathrm{M}_{x+n}\right)}} \cdot . \cdot . \cdot
$$

And this gives, for the same values of $x$ and $n$ as before, $P=6 \cdot 2828$. Or, finally, by omitting from (3) the factor $(1+r)^{\text {th }}$ we get for the value of $P$, when returnable at the end of the year of death, 6.26313 .

The benefit described in the problem, however, is altogether delnsive. It seems to have been devised with the object of enabling the parchaser to made a provision for advancing years, while retaining at the same time a certain amount of control over his capital. If so the object can be attained more simply and more efficaciously otherwise. Let the intending pnrchaser retain his capital in his own hands, and, when his necessities so require, let him invest its improved amount in an immediate anuuity, and he will find that he has done just as well as he wonld have done by the arrangement in the problem, while he has retained his control over both the capital and its interest.

To prove this:-Let the capital as before be $P$. Its amonnt in $n$ years will be $P(1+r)^{n}$; and, if this sum be invested in an annuity of $\mathfrak{E} 1$, we shall have

* This is very clearly pointed out by Mr. Younger at p. 55 ante. 
whence,

$$
\mathrm{P}(1+r)^{\mathbf{n}}=\frac{\mathrm{N}_{x+n}}{\mathrm{D}_{x+n}}
$$

$$
\mathrm{P}=\frac{\mathrm{N}_{x+n}}{(1+r)^{n} \mathrm{D}_{x+n}} \text {. . . . . . . }
$$

For $x=50$ and $x+n=60,(1)$ and (2) give, as we bave seen, $P=6.30295$; while (4) gives $P=6.52820$. This slight increase in the value of $\mathrm{P}$ is the equivalent for the advantage of being relieved from the risk of losing the interest in the event of death during the $n$ years.

For the proper solution of Mr. Stephenson's problem it is (or ought to be) obvious, that we require to know the law that governs the withdrawals as well as that which governs the mortality, the infuence upon the result exercised by the one of these elements being entirely analogons to that exercised by the other. In attempting a solution of the problem therefore, as a matter of scientific interest, it is necessary to assume a law of withdrawal. This is done by Mr. Younger in the solution given by him in the last number of the Journal, pp. 55 to 58 ; and in that which I am about to offer I shall employ the same law. Of Mr. Younger's solntion I shall now only say, that I consider the analysis he employs as of a much more refined character than the circumstances of the case require.

If $\lambda_{x}$ denote the number of policies at age $x$, the numbers of these remaining in foree at the end of $1,2, \ldots t-1$ years, will be denoted by $\lambda_{x+1}, \lambda_{x+2}, \ldots \lambda_{x+i-1}$, respectively. Now, let the law of withdrawal be, that the number of withdrawals in each year is the fraction $k$ of the number of policies in force at the beginning of the year; so shall the withdrawals during the 1 st, 2 nd . . t th years be severally denoted by $k \lambda_{x}$, $k \lambda_{x+1} \ldots k \lambda_{x+t-1}$. Let also the withdrawals of each year, and in like manner the deaths, be uniformly distributed over the year.

The decrement of the $t$ th year, if there were no withdrawals, would be the product of $\lambda_{x+t-1}$ by the probability of $(x+t-1)$ dying in a year. The withdrawals during the year are $k \lambda_{x+t-1}$, at equal intervals therein, which is equivalent, as regards the operation of mortality, to the whole taking place in the middle of the year; and this again is equivalent, in the same sense, to one-half taking place at the commencement of the year, and the other half at the end. Hence the number exposed to the risk of mortality daring the whole of the $t$ th year will be denoted by $\lambda_{x+t-1}-\frac{1}{2} / \lambda_{x+t-1}$, or $\lambda_{x+t-1}\left(1-\frac{1}{2} k\right)$, which gives for the portion of the decrement due to mortality $\lambda_{x+t-1}\left(1-p_{x+t-1}\right)\left(1-\frac{1}{2} k\right)$; and adding to this the portion due to withdrawals, $k \lambda_{x+1-1}$, we get for the total decrement of the $t$ th year,

Hence,

$$
\lambda_{x+t-1}\left\{\left(1-p_{x+t-1}\right)\left(1-\frac{1}{2} k\right)+k\right\} \text {. }
$$

$$
\begin{gathered}
\lambda_{x+t}=\lambda_{x+t-1}-\lambda_{x+t-1}\left\{\left(1-p_{x+t-1}\right)\left(1-\frac{1}{2} k\right)+k\right\} \\
=\lambda_{x+t-1}\left\{\left(1-\frac{1}{2} k\right) p_{x+t-1}-\frac{1}{2} k\right\} .
\end{gathered}
$$

And if we denote by $\varpi_{x+t-1}$ the probability that a policy in force at the beginning of the th year will not be extinguished that year, bat will remain in force at the end, we shall have

$$
\varpi_{x+t-1}=\frac{\lambda_{x+t}}{\lambda_{x+t-1}}=\left(1-\frac{1}{2} k\right) p_{x+t-1}-\frac{1}{2} k
$$


From the nature of this function we shall obvionsly have

$$
\lambda_{x+t}=\lambda_{x}, \varpi_{x}, \varpi_{x+1} \ldots \varpi_{x+t-1} \text {; }
$$

and hence, with any assnmed value of $\lambda_{x}$ as a radix, we shall be able to form with facility a table of the number of policies in force at the end of each successive year, up to age $x+n$, at which the power of withdrawal ceases. The number then in force being subject to diminution by mortality only, the portion of the table from this point will be identical with the corresponding portion of the mortality table if the radix $\lambda_{x}$ be so assumed that $\lambda_{x+n}$ shall equal $l_{x+n^{*}}$. This is a matter easily arranged.

Mr. Younger, in his example, employs the Carlisle mortality, and assumes $k=\frac{1}{20}==05$. I have formed the following table on the same hypotheses, to facilitate the comparison of my result with his. It coincides with the Carlisle table at 60 , the age at which, in Mr. Younger's example, the power of withdrawal ceases and the annnity is entered upon.

Policy Table.

\begin{tabular}{|c|c|c|c|c|}
\hline$x$ & $\lambda_{x}$ & $\begin{array}{l}\text { Deaths and } \\
\text { Withdrawals. }\end{array}$ & Deaths. & Withdrawals. \\
\hline $\begin{array}{l}50 \\
51 \\
52 \\
53 \\
54 \\
55 \\
56 \\
57 \\
58 \\
59 \\
60\end{array}$ & $\begin{array}{l}7380 \cdot 54 \\
6914 \cdot 96 \\
6472 \cdot 86 \\
6053 \cdot 30 \\
5655 \cdot 33 \\
5279 \cdot 39 \\
4923 \cdot 17 \\
4585 \cdot 82 \\
4263 \cdot 10 \\
3949 \cdot 34 \\
3643 \cdot 00\end{array}$ & $\begin{array}{l}465 \cdot 58 \\
442 \cdot 10 \\
419 \cdot 56 \\
397 \cdot 97 \\
375 \cdot 94 \\
356 \cdot 22 \\
337 \cdot 35 \\
322 \cdot 72 \\
313 \cdot 76 \\
306 \cdot 34 \\
122 \cdot 00\end{array}$ & $\begin{array}{r}96 \cdot 56 \\
96 \cdot 36 \\
95 \cdot 93 \\
95 \cdot 31 \\
93 \cdot 17 \\
92 \cdot 26 \\
91 \cdot 20 \\
93 \cdot 43 \\
100 \cdot 61 \\
108 \cdot 87 \\
122 \cdot 00\end{array}$ & $\begin{array}{l}369 \cdot 02 \\
345 \cdot 74 \\
323 \cdot 63 \\
302 \cdot 66 \\
282 \cdot 77 \\
263 \cdot 96 \\
246 \cdot 15 \\
229 \cdot 29 \\
213 \cdot 15 \\
197 \cdot 47\end{array}$ \\
\hline
\end{tabular}

This table, after what preceles, stands in need of no explanation. The last two colnmns, which show the deaths and withdrawals separately, have been added to afford the means of testing the accordance of the table with the laws used in its formation.

The most convenient way of adapting for use the data with which we are now furnished, will be to form by means of them a commutation table. This I have done as follows:-

Commutation Table.

\begin{tabular}{|c|c|c|c|}
\hline$x$. & $\mathrm{D}_{x^{*}}$ & $\mathrm{~N}_{x^{*}}^{\prime}$ & $\mathrm{M}_{x^{*}}$ \\
\hline 50 & $1038 \cdot 536$ & $9385 \cdot 130$ & $637 \cdot 625$ \\
51 & $\mathbf{9 3 5 \cdot 6 0 0}$ & $8449 \cdot 530$ & $574 \cdot 632$ \\
52 & $842 \cdot 097$ & $7607 \cdot 433$ & $517 \cdot 116$ \\
53 & $757 \cdot 225$ & $6850-208$ & $464 \cdot 632$ \\
54 & $680 \cdot 233$ & $6169 \cdot 975$ & 416763 \\
55 & $610 \cdot 591$ & $5559 \cdot 384$ & $373 \cdot 284$ \\
56 & $547 \cdot 492$ & $5011 \cdot 892$ & $333 \cdot 670$ \\
57 & $490 \cdot 362$ & $4521 \cdot 530$ & $297 \cdot 597$ \\
58 & $438 \cdot 321$ & $4083 \cdot 209$ & $264 \cdot 415$ \\
59 & $390 \cdot 443$ & $3692 \cdot 766$ & $233 \cdot 396$ \\
60 & $346 \cdot 305$ & $3346 \cdot 461$ & $204 \cdot 275$ \\
\hline
\end{tabular}


The rate of interest involved is 4 per cent., and the table coincides with Mr. Jones's Table XIII. (p. 295), at age 60. To distinguish values affected by withdrawal, I accent the letters designating the columns in which they are found. It is, of course, indifferent whether the values belonging to age 60 be accented or not.

The table is adapted to the treatment of any case in which $x$ is not less than 50 and the age at which the annuity is to be entered upon is 60 . In Mr. Younger's example $x$ is 50; and the formula of solution is evidently (3), which for these values of $x$ and $x+n$ becomes

$$
\mathrm{P}=\frac{\mathrm{N}_{60}^{\prime}}{\mathrm{D}_{50}^{\prime}-(1 \cdot 04)^{\prime}\left(\mathrm{M}_{50}^{\prime}-\mathrm{M}_{60}^{\prime}\right)}
$$

The arithmetical operation is as follows:-

$$
\begin{aligned}
& \mathrm{M}_{50}^{\prime} \quad 637 \cdot 625 \\
& \mathrm{M}_{60}^{\prime} 204.275 \\
& 433.350 \log 2 \cdot 636839 \\
& (1.04)^{\frac{1}{2}}, 0.008517 \\
& 441.933, \overline{2 \cdot 645356} \\
& D_{50}^{\prime} \quad 1038.536 \\
& 596 \cdot 603,2 \cdot 775685 \\
& \mathrm{~N}_{60}^{\prime} \quad 3346.46 \quad \text { "3.524586 } \\
& \text { P } 5.60920, \overline{0.748901}
\end{aligned}
$$

The value here fonnd for $P, 5 \cdot 60920$, is less than that given by (3), 6.2828 , which is the value when there are to be no withdrawals. Mr. Younger, however, finds for it $9 * 4157$, which is no less than 50 per cent. greater than that given by (3), as above; and he intimates his opinion that this is what onght to be. It appears to me likely that the opinion thus indicated is merely an inference from his numerical result, since a very little consideration suffices to show that the value here ought to be less than that given by (3), and not greater. Every extinction of a policy previous to the age at which the annuity is to be entered upon (and for some years after) is a decision of the risk on the policy extinguished, in favour of the Office; and hence the introdnction of a condition that will increase the number of such extinctions requires and necessitates, for the preservation of the equitable character of the transaction, a diminntion and not an increase of the preminm. The power to withdraw is thus not a privilege accorded to the policy-holder, and for which he ought to be made to pay, but a concession made by him, in consenting to abandon his claim to the annuity in consideration of receiving back only the preminm he has paid. This being so, then, it follows that Mr. Younger must have fallen into error in his solntion of the problem. That he has done so I proceed to show.

We have seen that the expression (3), which, if applied by mens of the ordinary table, gives the valne of $\mathbf{P}$ when there are to be no withdrawals, gives the value also, if applied by means of $a$ suitable table when there are to be withdrawals. The expression is

$$
\mathrm{P}=\frac{\mathrm{N}_{x+n}}{\mathrm{D}_{x}-(1+r)^{\frac{1}{\mathrm{~B}} \mathrm{M}_{x \mid n}}}
$$


and it becomes, on division of numerator and denominator by $\mathbf{D}_{x}$,

$$
\mathrm{P}=\frac{1}{1-\frac{(1+r)^{\frac{1}{\mathrm{M}} \mathrm{M}_{x \mid n}}}{\mathrm{D}_{x}}} \cdot \frac{\mathrm{N}_{x+\mathrm{n}}}{\mathrm{D}_{x}} ;
$$

or, writing $Q$ for $\frac{(1+r)^{2} M_{x \mid n}}{D_{x}}$, which is the value of a return of $£ 1$,

$$
P=\frac{1}{1-Q} \cdot \frac{N_{x+n}}{D_{x}}
$$

This is Mr. Younger's expression, which, being thus identical with mine, ought, if properly applied-if the proper values of the elements composing it be made use of-to give the same numerical result. Mr. Younger, by an analytical process, which $I$ think I am warranted in calling unnecessarily refined, determines an expression for $Q$ which enables him to assign $\cdot 42556$ as its value in the case in hand, which value differs but little from that given by my table-namely, -425534 . It is in the remaining element of the expression then-the annuity valne-that the principal source of the discrepancy must be sought. Accordingly we find that $\mathrm{Mr}$. Younger here uses the ordinary deferred annuity value; and in so doing-ignoring one of the contingencies on which, during the first 10 years, the valne of the annuity depends-he, singnlar to say, commits an error precisely similar in character to that which he points out as vitiating $\mathrm{Mr}$. Stephenson's investigation. The effect is, that the ralne thrs assigned to $P$ is one that will provide an annuity not only for those who neither die nor withdraw during the 10 years, but also for such of the latter class as shall survive the term!

Using the annnity value derived from my table, and Mr. Younger's value of $\mathrm{Q}$ (in which there is probably some arithmetical error), his formula gives for $\mathrm{P}, 5.60944$." Using also ny value of $Q$, it gives, of course, $5 \cdot 60920$.

I must apologise for having occupied so mnch space. I hope, however, it may be found that something has been done towards the elucidation of the various points of interest that have arisen.

$$
\text { I am, Sir, }
$$

Yours most obediently,

London, 11 th May, 1866.

P. GRAY.

\section{ON MR. YOUNGER'S LETTER, AND ON THE GENERAL SOLUTION OF PROBLEMS INVOLVING DISTINCT CONTINGENCIES.}

\section{To the Editor.}

Sir,-After the non-snccess of my endeavour to convince Mr. Stephenson of the failure of his attempt to solve a new problem in life contingencies, I declared my intention of retiring from the contest; as I felt satisfied that a continnance of the discussion with an opponent who (in the face of the evidence I had adduced) still adhered to his notion that he had succeeded in determining the value of the "option of withdrawal," was not likely to lead to any useful result. The snbject, however, having been taken up by Mr. Younger, in an able letter published in your last Number, wherein that gentleman (after endeavouring to point out the source of Mr. Stephenson's

* See Mr. Younger's letter, p. 118, - ED. J. I. A.

vOL. XIII, 